\title{
lonic wind generation by a wire-cylinder-plate corona discharge in air at atmospheric pressure
}

\author{
Dorian F. Colas, ${ }^{\text {a) }}$ Antoine Ferret, David Z. Pai, Deanna A. Lacoste, and \\ Christophe O. Laux \\ Laboratoire EM2C, UPR 288, CNRS, École Centrale Paris, Grande Voie des Vignes, 92290 Châtenay- \\ Malabry, France
}

(Received 13 August 2010; accepted 10 October 2010; published online 29 November 2010)

\begin{abstract}
A wire-cylinder-plate electrode configuration is presented to generate ionic wind with a dc corona discharge in air at atmospheric pressure. The objective of the work is to maximize the power supplied to the flow in order to increase acceleration while avoiding breakdown. Thus, the proposed experimental setup addresses the problem of decoupling the mechanism of ion generation from that of ion acceleration. Using a wire-plate configuration as a reference, we have focused on improving the topography of the electric field to (1) separate the ionization and acceleration zones in space, and (2) guide the trajectory of charged particles as parallel to the median axis as possible. In the proposed wire-cylinder-plate setup, a dc corona discharge is generated in the space between a wire and two cylinders. The ions produced by the corona then drift past the cylinders and into a channel between two plates, where they undergo acceleration. To maximize the ionic wind it is found that the geometric configuration must be as compact as possible and that the voltage applied must be right below breakdown. Experimentally, the optimized wire-plate reference setup provides a maximum flow velocity of $8 \mathrm{~m} \mathrm{~s}^{-1}$, a flow rate per unit electrode length of $0.034 \mathrm{~m}^{2} \mathrm{~s}^{-1}$, and a thrust per unit electrode length of $0.24 \mathrm{~N} \mathrm{~m}^{-1}$. The wire-cylinder-plate configuration provides a maximum flow velocity of $10 \mathrm{~m} \mathrm{~s}^{-1}$, a flow rate per unit electrode length of $0.041 \mathrm{~m}^{2} \mathrm{~s}^{-1}$, and a thrust per unit electrode length of $0.35 \mathrm{~N} \mathrm{~m}^{-1}$. This $46 \%$ increase in thrust is obtained by increasing the electric power per unit electrode length by only $16 \%$ (from 175 to $210 \mathrm{~W} \mathrm{~m}^{-1}$ ), which confirms the gain in efficiency obtained with the decoupled system. In comparison with a simple wire-wire corona configuration, the wire-cylinder-plate configuration increases the ionic wind velocity by up to a factor of 3, and the thrust by an order of magnitude. (C) 2010 American Institute of Physics. [doi:10.1063/1.3514131]
\end{abstract}

\section{INTRODUCTION}

The effect of the ionic wind created by a plasma discharge has interesting potential applications for external and internal flow control. In external flows such as in the boundary layer of an airfoil, plasma discharges can be used for the purpose of reducing drag, increasing lift during takeoff and landing, controlling the transition to turbulence, and flow actuation. ${ }^{1-3}$ Regarding internal flows, plasma actuators also show promising preliminary results. In turbomachinery for example, current research to control separation on turbine blades and tip clearance flows to decrease losses and prevent rotating stall could lead toward more efficient and thus lighter engines. ${ }^{4-6}$

The two types of plasma discharges commonly employed to generate the ionic wind are the dielectric barrier discharges (DBD) and the corona discharges between two parallel wires placed perpendicularly to the direction of the flow (CD). ${ }^{7-12}$ In these studies where DBDs have been used as the basis to form several alternative types of discharges such as the Single DBD (SDBD), the maximum induced flow speed is about $7 \mathrm{~m} \mathrm{~s}^{-1}$ and the maximum thrust per unit electrode length is about $0.250 \mathrm{~N} \mathrm{~m}^{-1}$ (Ref. 8). A significant

${ }^{a)}$ Electronic mail: dcolas@mit.edu. increase of the level of thrust generated per unit electrode length is however necessary for applications in high speed flow control. ${ }^{6}$

We examine here several configurations using a corona discharge. The principle of the ionic wind produced by a corona between two cylindrical wires can be explained as follows. ${ }^{13}$ Around each wire, the electric field decreases inversely proportional to the distance to the wire. For small wire diameters, the electric field in the vicinity of the wire brought to a high potential is sufficient to ionize air. The positive ions generated at the anode drift toward the cathode while the negative ions stay close to the anode. In their movement, the positive ions transfer momentum to the neutral molecules via collisions. At the vicinity of the cathode, electrons attach to oxygen, and $\mathrm{O}_{2}^{-}$drifts toward the anode, transferring momentum to the neutrals. Two opposite charge currents appear. The net flow is called the ionic wind. When the electrodes are asymmetric (e.g., small diameter anode and large diameter cathode), the positive ion current dominates and the effect of the ionic wind is maximum.

Two types of DC corona discharges have been previously used for ionic wind generation. The first type is a DC surface corona discharge produced between two wires placed on the surface of an airfoil. This setup has been studied under various aerodynamic conditions and has proven to generate 


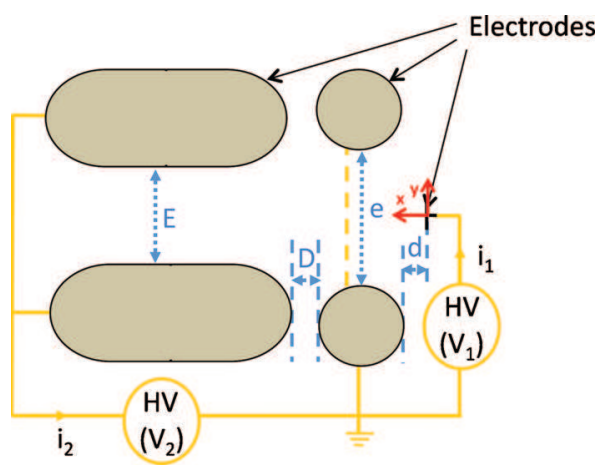

FIG. 1. (Color) Setup for the new wire-cylinder plate configuration.

speed flows up to $5 \mathrm{~m} \mathrm{~s}^{-1}$. The second type is a dc corona discharge between two free-standing wire electrodes in air. ${ }^{12}$ In Ref. 12, Berard et al. showed that flow velocities up to $3.5 \mathrm{~m} \mathrm{~s}^{-1}$ could be generated. Higher velocities could not be attained because the power supplied to the fluid was limited by the occurrence of sparks between the electrodes. One major problem with these two configurations of DC corona discharges is that the ionization and acceleration processes are coupled.

The present investigation extends previous works in which the authors studied a wire-wire configuration and proposed a preliminary wire-plates configuration as a way to increase the flow rate over the more traditional wire-wire configuration. ${ }^{12,13}$ We will see that our optimized wire-plates reference configuration provides a flow velocity of up to $8 \mathrm{~m} \mathrm{~s}^{-1}$ and that the proposed wire-cylinder-plate configuration further increases the flow velocity up to $10 \mathrm{~m} \mathrm{~s}^{-1}$ by decoupling the mechanism of ionization from that of acceleration. The latter configuration also increases the thrust up to $0.35 \mathrm{~N} \mathrm{~m}^{-1}$, i.e., $40 \%$ higher than in all previous studies with SDBDs or CDs. This level of thrust may be sufficient for applications in turbomachinery. ${ }^{6}$

\section{PROPOSED CONCEPT}

In the baseline wire-wire configuration studied in Ref. 12 , the electric field profile between the wires is responsible for both acceleration and ionization. The energy deposited is limited by the appearance of a spark. To increase the velocity of the flow, one should increase the number of charged particles and/or the electric field.

Our objective here is to decouple ionization and acceleration. To this end, we create an ionization zone between a wire brought to a positive potential $\mathrm{V}_{1}$ and a pair of cylindrical electrodes connected to ground, and an acceleration zone between the cylinders and a pair of parallel plates brought to a negative potential $\mathrm{V}_{2}$ (see Fig. 1). To maximize ionization, we set the electric field at the anode close to its maximum value (i.e., just below breakdown). To maximize acceleration, we seek to make the electric field lines as parallel to the $x$-axis as possible. This study was performed using the finite element method-based software COMSOL MULTIPHYSICS $^{\circledR}$ which provided 2D simulations of the electrostatic field for various electrode configurations (i.e., number of electrodes, their overall shapes and relative positions). ${ }^{14}$ The adjustable parameters were e, E, D, and d.

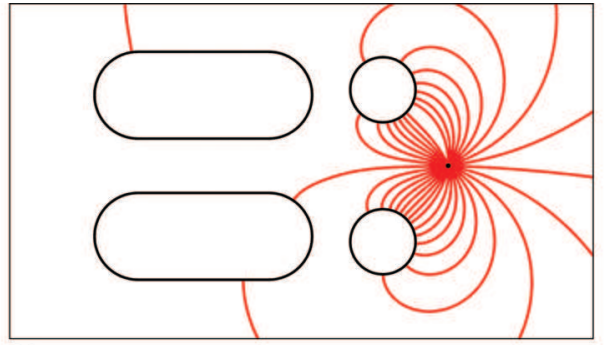

(a)

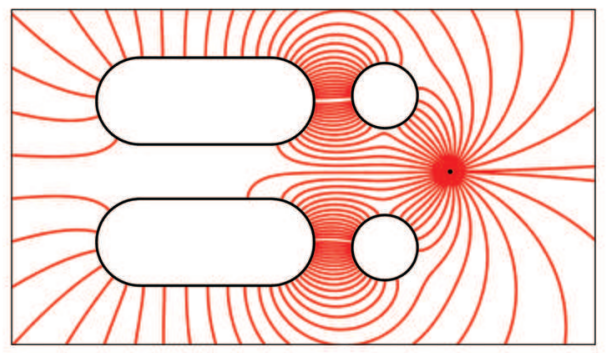

(b)

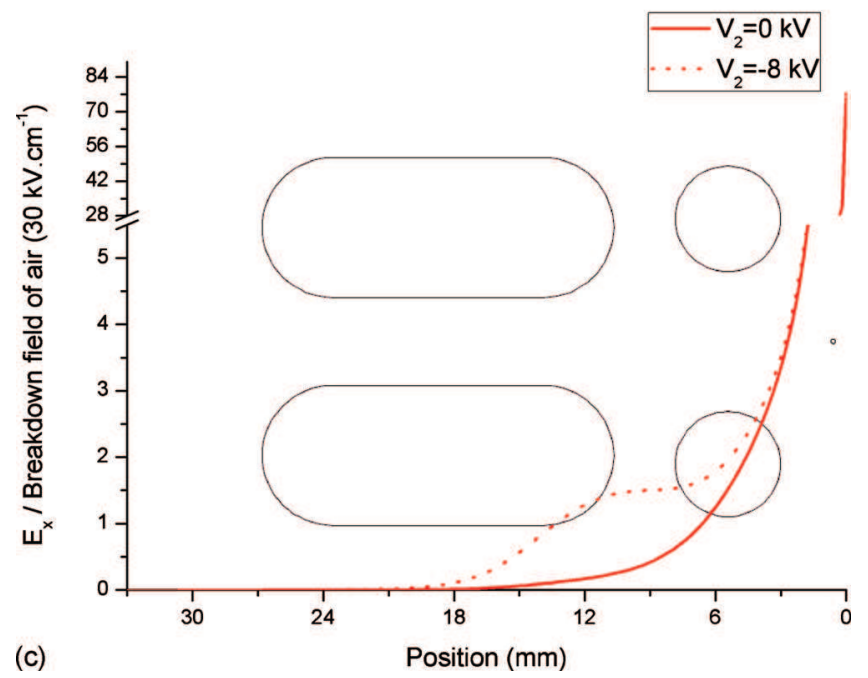

FIG. 2. (Color) For the parametrically optimized configuration (see section IV, $E=5 \mathrm{~mm}, \mathrm{e}=8 \mathrm{~mm}, \mathrm{D}=4 \mathrm{~mm}$, and $\mathrm{d}=3 \mathrm{~mm}$ ): [(a) and (b)] Computed electric field lines for $\mathrm{V}_{2}=0 \mathrm{kV}$ (a) and $\mathrm{V}_{2}=-8 \mathrm{kV}$ (b). Fixed $\mathrm{V}_{1}$ $=15 \mathrm{kV}$. (c) Computed electric field component along the $x$-axis (solid red: $\mathrm{V}_{2}=0 \mathrm{kV}$, dashed red: $\mathrm{V}_{2}=-8 \mathrm{kV}$ ). Fixed $\mathrm{V}_{1}=15 \mathrm{kV}$.

The radii of curvatures of the electrodes were set equal to 3 $\mathrm{mm}$ except for the wire's, being set at $0.2 \mathrm{~mm}$. This choice is motivated by the conclusions drawn from a previous study: to maximize the ionic wind, the electrode diameter dissymmetry the largest. ${ }^{12}$

Figures 2(a) and 2(b) show the results of the COMSOL simulations. As can be seen from these figures, the application of $\mathrm{V}_{2}$ creates electric field lines parallel to the $x$-axis, thus promoting a zone of strong acceleration between the cylinders and the plates. There are now two spatial zones in which the electric field has different effects: a first zone between the wire and the cylinders where the field ionizes and provides a first acceleration of the flow, and a second zone between the cylinders and the plates where only acceleration occurs. Figure 2(c) shows the component of the electric field along the $x$-axis, as computed with COMSOL, and normalized by the breakdown electric field in air $\left(3 \times 10^{5} \mathrm{~V} \mathrm{~m}^{-1}\right)$. As 
(a)
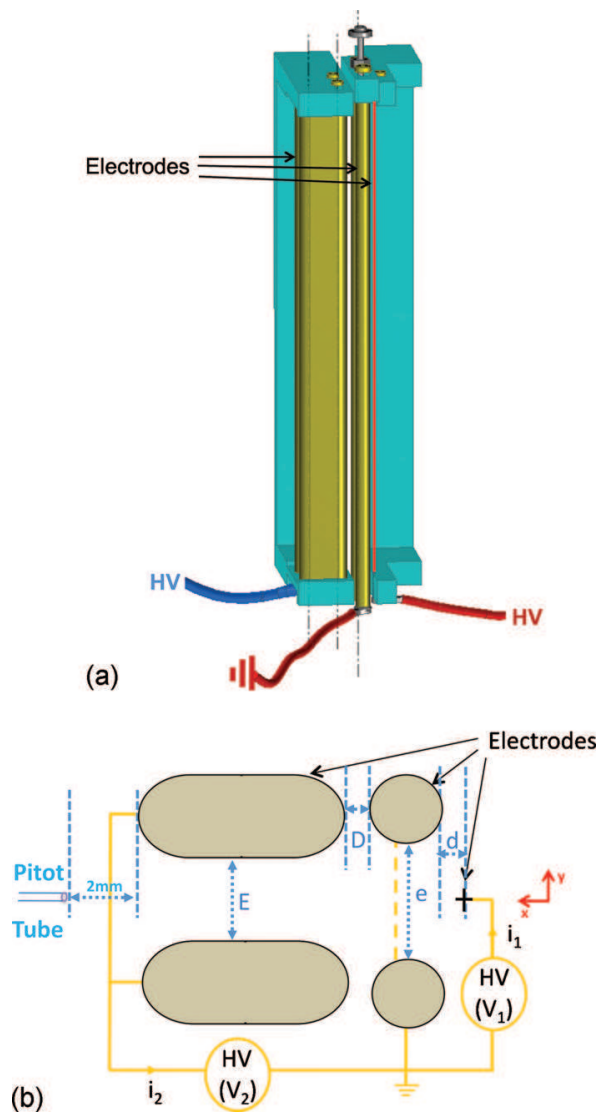

FIG. 3. (Color) [(a) and (b)] Experimental setup for the new wire-cylinder plate configuration showing the electrical circuit with the primary $\left(\mathrm{V}_{1}\right)$ and secondary $\left(\mathrm{V}_{2}\right)$ power supplies.

can be seen from Fig. 2(c), the secondary power supply $\left(\mathrm{V}_{2}\right)$ raises the electric field in the space between the plates and the cylinders by almost one order of magnitude, thus increasing the momentum of the charged particles along the $x$-axis, and therefore, increasing the flow velocity. We will now test this concept experimentally.

\section{EXPERIMENTAL SETUP}

To test the concept proposed in section II, the experimental setup shown in Fig. 3 was used. This setup is comprised of a wire, two parallel cylinders and two parallel plates of $20 \mathrm{~cm}$ length in air at atmospheric pressure and ambient temperature. The adjustable parameters are the various gap distances and the voltages $V_{1}$ and $V_{2}$. The wire is made of steel and all other electrodes of brass. The diameters of the wire and cylinders are $0.2 \mathrm{~mm}$ and $6 \mathrm{~mm}$, respectively, and the plate cross-sectional dimensions are $8 \times 20 \mathrm{~mm}^{2}$, with rounded edges to avoid spurious breakdown.

The gap between the wire and the cylinders is adjustable from 0.3 to $4 \mathrm{~cm}$. So is the gap between the cylinders and the plates. The wire electrode is raised to a positive dc potential adjustable up to $20 \mathrm{kV}$ with a FUG $140-20000$ primary power supply. The cylinders are connected to ground. The plates are brought to a negative dc potential of up to $-15 \mathrm{kV}$ with a secondary power supply. We measured the currentvoltage characteristics and the flow velocities as a function of the applied potentials. The currents and voltages were

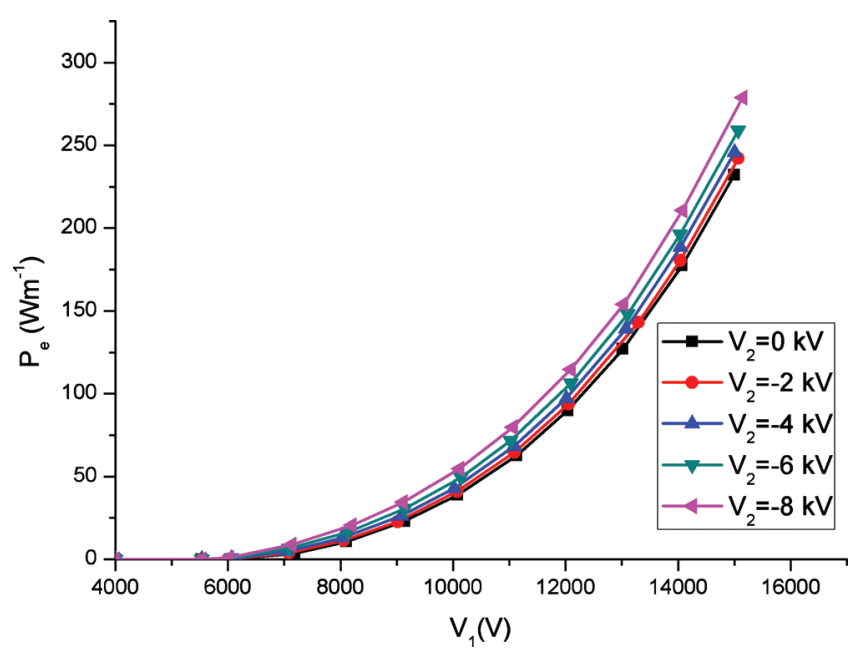

FIG. 4. (Color) Electric power (per unit electrode length) transferred to the fluid as a function of $\mathrm{V}_{1}$ for different values of $\mathrm{V}_{2}$.

obtained from the digital readouts of the power supplies. The flow velocities were measured with a glass Pitot tube connected to a differential manometer of resolution $0.1 \mathrm{~Pa}$. The orifice of the Pitot tube was placed $2 \mathrm{~mm}$ downstream of the exit plane of the plates. The wire-plate reference configuration is obtained by removing the cylinders and grounding the plates.

\section{EXPERIMENTAL RESULTS}

A parametric study was conducted to maximize the ionic wind velocity as a function of the electrode gap distances and potentials. The study confirmed results previously obtained in Ref. 12, namely that the maximum current is obtained for the most compact configuration possible. However, all the interelectrode gap distances should not be too small, otherwise sparks appear or the plates become an obstacle to the flow. Thus, we chose the following optimized parameters: $\mathrm{E}=5 \mathrm{~mm}, \mathrm{e}=8 \mathrm{~mm}, \mathrm{D}=4 \mathrm{~mm}$, and $\mathrm{d}=3 \mathrm{~mm}$.

We will now present the electrical and mechanical characteristics of the optimized wire-cylinder-plate setup. The optimized wire-plate reference configuration gives the same results as the wire-cylinder-plate configuration with $\mathrm{V}_{2}$ $=0 \mathrm{kV}$.

The electric power by unit electrode length $\mathrm{P}_{\mathrm{e}}$ transferred to the fluid can be obtained as follows:

$$
\mathrm{P}_{\mathrm{e}}=\frac{1}{\mathrm{~h}}\left(\mathrm{P}_{1}+\mathrm{P}_{2}\right)=\frac{1}{\mathrm{~h}}\left(\mathrm{~V}_{1} \mathrm{i}_{1}+\mathrm{V}_{2} \mathrm{i}_{2}\right),
$$

where $\mathrm{P}_{1}$ and $\mathrm{P}_{2}$ correspond to the electric power generated by the primary and secondary power supplies and $\mathrm{h}$ to the length of the electrodes $(\mathrm{h}=20 \mathrm{~cm})$.

As shown in Fig. 4, the maximum potential $V_{1}$ that can be applied to the anode is independent of the potential $\mathrm{V}_{2}$ applied to the plates. This can be understood from the COMSOL simulations: the electric field imposed by $\mathrm{V}_{1}$ at the wire surface is about $200 \mathrm{kV} \mathrm{cm}^{-1}$, whereas the field superimposed with the secondary power supply is only $6 \mathrm{kV} \mathrm{cm}^{-1}$, which does not significantly affect the total field at the anode surface and thus the level of ionization. In summary, increas- 

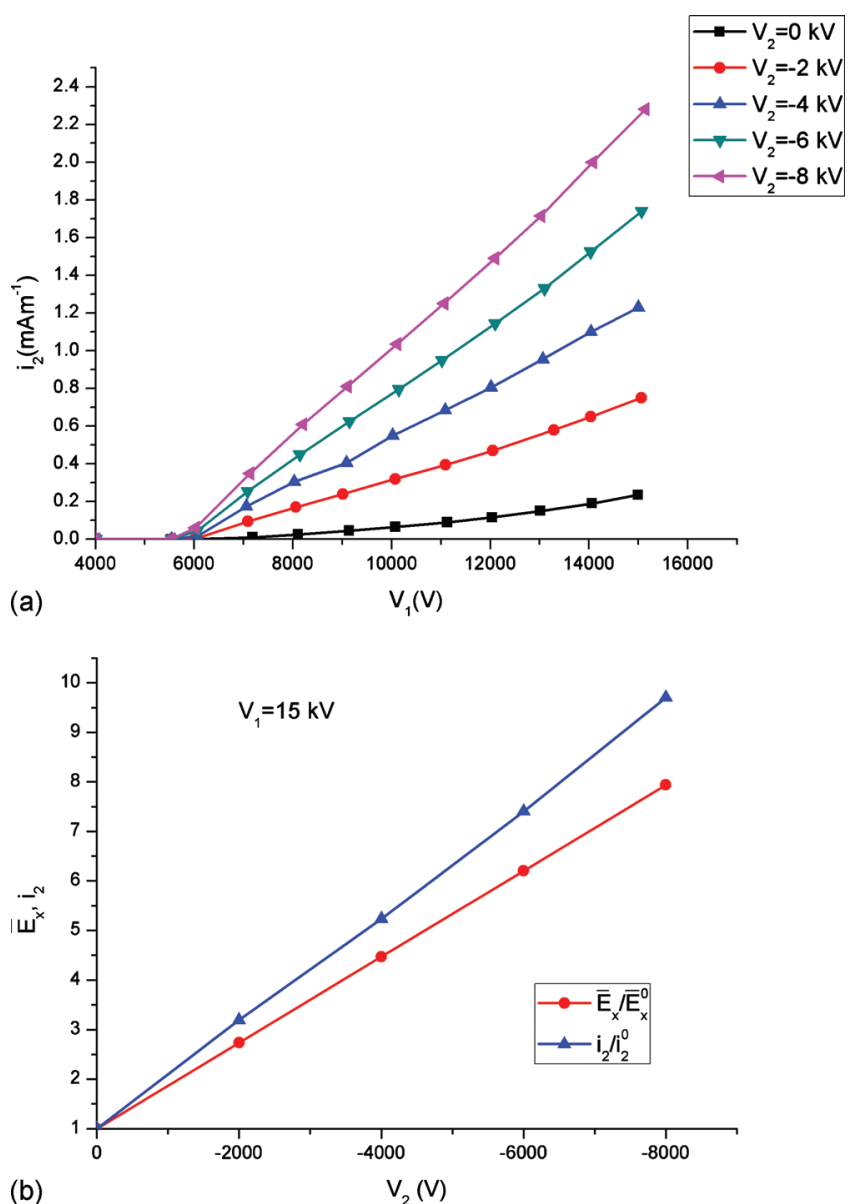

(b)

FIG. 5. (Color) (a) Influence of $\mathrm{V}_{1}$ on $\mathrm{i}_{2}$ for different values of $\mathrm{V}_{2}$, (b) Comparison between the influence of $\mathrm{V}_{2}$ on the normalized mean electric field and on the normalized $i_{2} . i_{20}$ corresponds to the measured value of $i_{2}$ for $\mathrm{V}_{1}=15 \mathrm{kV}, \mathrm{V}_{2}=0 \mathrm{kV}\left(\mathrm{i}_{2}^{0}\right)=0.24 \mathrm{~mA} \mathrm{~m}^{-1}, \mathrm{E}_{\mathrm{x}}^{0}$ corresponds to the mean component along $x$ of the electric field computed with COMSOL in the region contained between the two plates [see Fig. 2(c)].

ing $\mathrm{V}_{2}$ increases the power deposited into the fluid without inducing sparking.

Figure 5(a) shows that the increase of $V_{2}$ has a direct influence on $\mathrm{i}_{2}$, the current between the cylinders and the plates. The increase in current could be the result either of a higher acceleration of the positive ions moving toward the plates, and/or of an increase in their number density. If $\mathrm{i}_{2}$ were related to the velocity of the positive ions that do not end up adsorbed on the plates, then it should depend linearly on the mean electrical field along the $x$ axis. This is indeed the case, as Fig. 5(b) shows a linear dependence of both the mean electrical field between the electrodes and of $i_{2}$ on $V_{2}$. Thus, the effect of the secondary power supply is not to increase the ionization level, but rather to produce additional acceleration of the positive ions.

Figure 6 shows the flow velocity measured with the Pitot tube along the axis of the system at $2 \mathrm{~mm}$ downstream of the plates, as a function of the total applied electric power. For a given value of the applied electric power, we notice that the more negative the potential $\mathrm{V}_{2}$, the higher the flow velocity. Thus the electric energy is more efficiently transferred through $\mathrm{V}_{2}$ than through $\mathrm{V}_{1}$.

To quantify the benefits afforded by the new setup, we

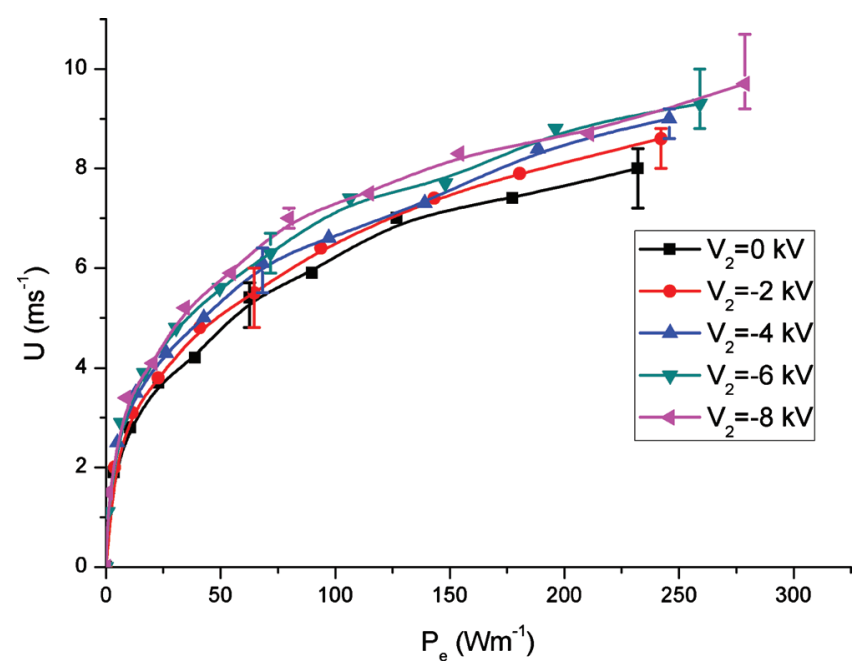

FIG. 6. (Color) Flow velocity measured $2 \mathrm{~mm}$ downstream of the plates as a function of the applied power for various values of $\mathrm{V}_{2}$.

measured the velocity profiles at the exit plane of the two plates. These velocity profiles are shown in Fig. 6(a) for various values of $V_{2}$. As can be seen from Fig. 7(a), the increase in $\mathrm{V}_{2}$ results in an increase of both the velocity and the flow rate.

With these measurements, we can calculate the generated thrust per unit length of electrode using

$$
\mathrm{T}=\frac{1}{\mathrm{~h}} \iint_{\mathrm{S}} \rho_{\text {air }} \mathrm{U}^{2} \mathrm{dS}=\int_{\mathrm{L}} \rho_{\text {air }} \mathrm{U}^{2} \mathrm{dy},
$$

where $U$ is the velocity profile measured $2 \mathrm{~mm}$ downstream of the exit of the plates $L$ the width of the exhaust jet at the measurement station, and $\mathrm{S}$ the exit surface area of the plates $(\mathrm{S}=\mathrm{h} \times \mathrm{L})$.

The thrust values, plotted in Fig. 7(b), are forty percent higher than the typical values reported for SDBD discharges on a flat plate. $^{7-9}$ The lower thrust measured for SDBD discharges on a plate or an airfoil is at least partly due to the viscous drag forces in the boundary layer of the surface where the SDBD is generated. ${ }^{15}$

To evaluate the efficiency of the wire-plates and wirecylinders-plates configuration, we introduce the mechanical power output per unit length of electrode, as follows:

$$
\mathrm{P}_{\mathrm{m}}=\int_{\mathrm{L}} \rho_{\mathrm{air}} \mathrm{U}^{3} \mathrm{dy},
$$

We also define the efficiency of the wire-cylinders subsystem responsible for ionization and part of the acceleration, as follows:

$$
\eta_{1}=\frac{\mathrm{P}_{\mathrm{m}}^{\mathrm{V}_{2}=0 \mathrm{kV}}}{\mathrm{P}_{1}},
$$

the efficiency of the cylinders-plates subsystem that provides secondary acceleration, as follows:

$$
\eta_{2}=\frac{\mathrm{P}_{\mathrm{m}}^{\mathrm{V}_{2}}-\mathrm{P}_{\mathrm{m}}^{\mathrm{V}_{2}=0 \mathrm{kV}}}{\mathrm{P}_{2}},
$$

and finally the efficiency of the overall system, as follows: 

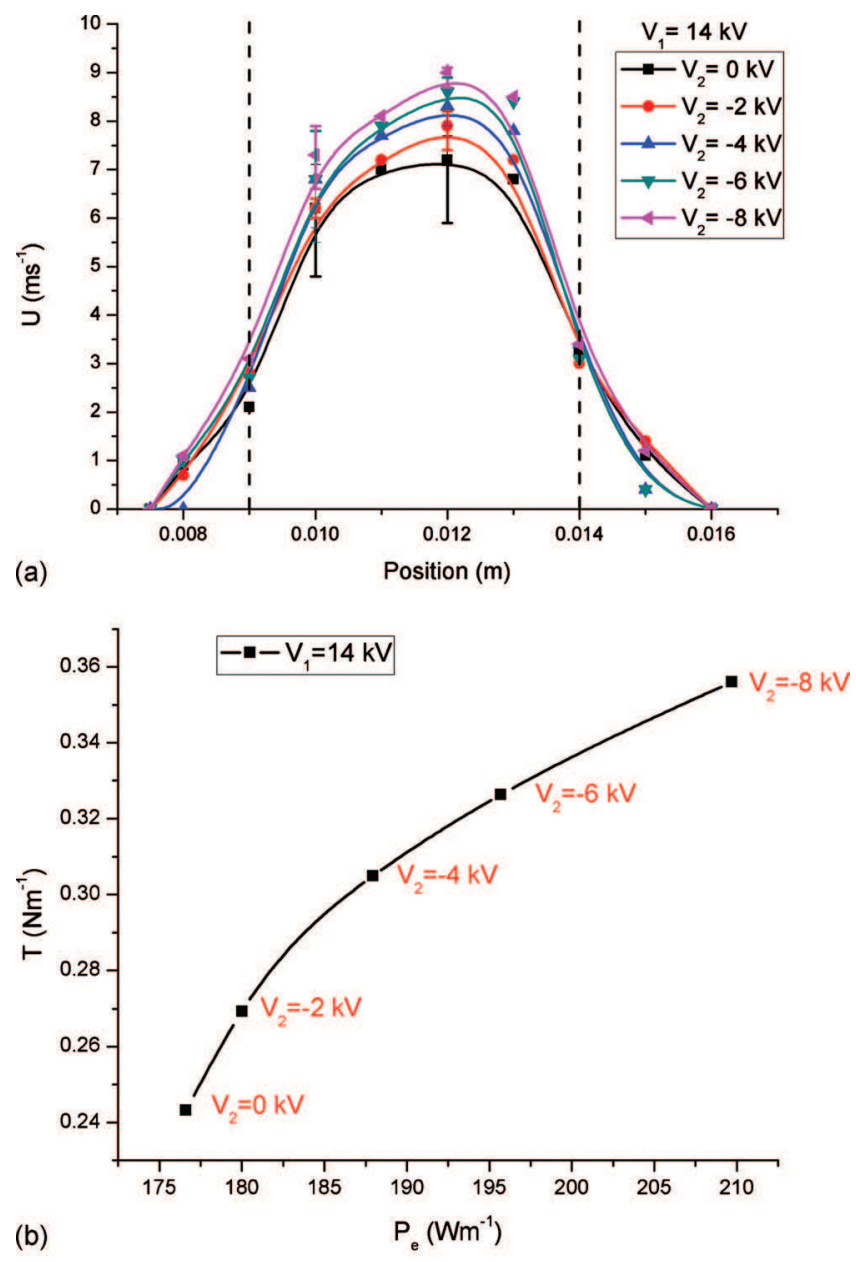

(b)

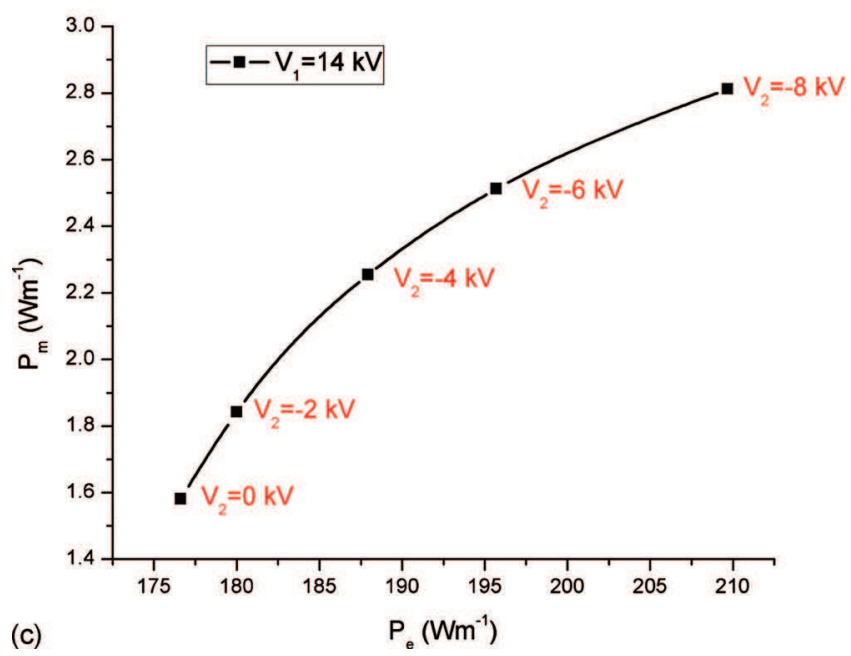

(c)

FIG. 7. (Color) (a) Lateral flow velocity profile $2 \mathrm{~mm}$ downstream of the plates (the dashes represent the position of the plates). (b) Thrust as a function of the electrical power for varying $\mathrm{V}_{2}$. (c) Mechanical power as a function of the electrical power for varying $\mathrm{V}_{2}$.

$$
\eta=\frac{\mathrm{P}_{\mathrm{m}}}{\mathrm{P}_{\mathrm{e}}} .
$$

Figure $7(\mathrm{c})$ shows that a $16 \%$ increase (from 175 to $210 \mathrm{~W} \mathrm{~m}^{-1}$ ) of the total applied electric power through the increase of $\mathrm{V}_{2}$ (i.e., $\mathrm{P}_{2}$ ) leads to a $78 \%$ increase in the mechanical power. Thus the secondary power supply is particularly efficient in increasing the acceleration of the flow.

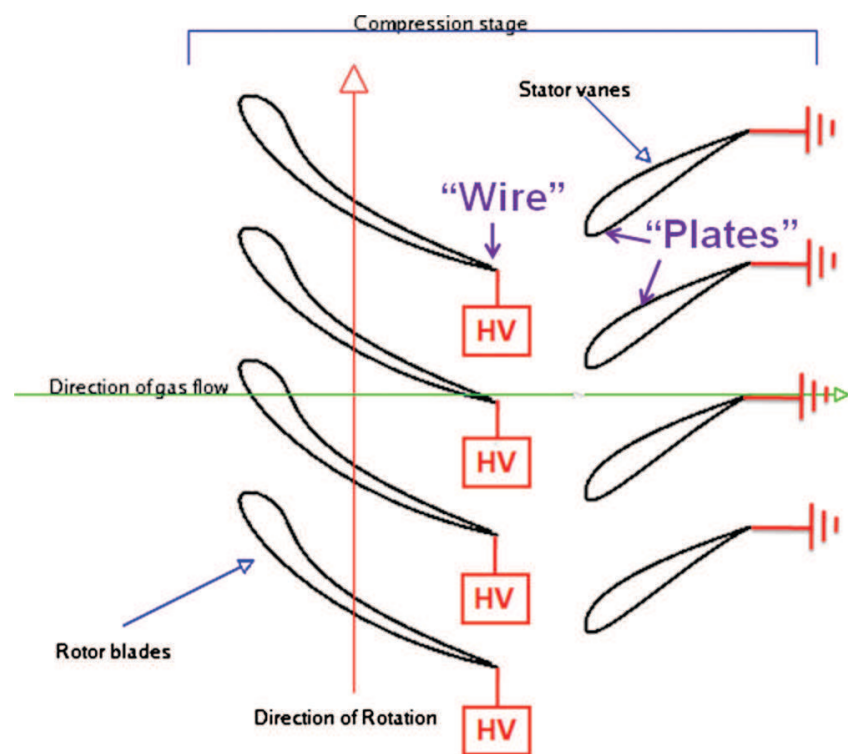

FIG. 8. (Color) External flow control potential application: compression stage of a turbo machine.

We can now quantify the efficiencies of both power supplies. The value of $\eta_{2}$ is $7.7 \%$, whereas the value of $\eta_{1}$ is only $0.9 \%$. The overall efficiency rises from $0.9 \%\left(\mathrm{~V}_{2}\right.$ $=0 \mathrm{kV})$ to $1.3 \%\left(\mathrm{~V}_{2}=-8 \mathrm{kV}\right)$. Since $\mathrm{V}_{2}$ is responsible only for acceleration and $\mathrm{V}_{1}$ for both acceleration and ionization, the difference between $\eta_{1}$ and $\eta_{2}$ may come from either a low efficiency of the ionization process or/and a higher efficiency of the acceleration produced by $V_{2}$ than by $V_{1}$.

Regarding the ionization efficiency, it is well known that most of the energy around the anode serves to excite the vibrational and electronic states of molecular species, in particular molecular nitrogen, rather than to ionize. ${ }^{16}$ Thus the ionization efficiency is expected to be small.

Regarding the acceleration efficiencies, we can see from Figs. 3(a) and 3(b) that the electric field created by $V_{1}$ (between the wire and the cylinders) is mostly nonparallel to the $x$-axis. This represents a loss of energy since the macroscopic flow is directed along the $x$-axis. In contrast, the electric field created by $\mathrm{V}_{2}$, i.e., the secondary acceleration zone between the cylinders and the plates has been shaped to be as parallel to the $x$-axis as possible. Thus the acceleration promoted by $\mathrm{V}_{2}$ is expected to be more efficient than the acceleration promoted by $\mathrm{V}_{1}$.

The thrust values obtained here are significantly higher than with these other setups, thus opening new possibilities for flow control. Figure 8 shows an example of internal flow geometry for which the present setup could be applied.

\section{CONCLUSIONS}

In this paper, we have presented and optimized a wireplates reference configuration to generate high flow velocities up to $8 \mathrm{~m} \mathrm{~s}^{-1}$, a flow rate by unit electrode length of up to $0.034 \mathrm{~m}^{2} \mathrm{~s}^{-1}$, and a thrust by unit electrode length of up to $0.24 \mathrm{~N} \mathrm{~m}^{-1}$. This value of the thrust is $40 \%$ higher than the highest values of thrust obtained with SDBDs, and could open interesting applications in turbomachinery or other internal flow configurations. 
We then proposed a wire-cylinders-plates configuration that further increases the ionic wind velocity by decoupling the mechanism of acceleration from that of ionization. Even though there is room for improvement in the electrodes' radii, two main results are obtained with this configuration. First, we are able to deposit more energy to accelerate the flow. This provides an increased flow velocity of up to $10 \mathrm{~m} \mathrm{~s}^{-1}$, flow rate and thrust generated by unit electrode length of up to $0.041 \mathrm{~m} \mathrm{~s}^{-1}$ and $0.35 \mathrm{~N} \mathrm{~m}^{-1}$, respectively. This value of the thrust is $46 \%$ higher than for the reference configuration. Second, the efficiency of the acceleration process being much higher than the efficiency of ionization, the overall efficiency of the new configuration increases significantly: the $46 \%$ increase in thrust is obtained by increasing the electric power by only $16 \%$.

To obtain higher velocities, one possible improvement would be to increase the efficiency of the ionization process. This is currently investigated through the use of nanosecond repetitively pulsed discharges as previously proposed for corona discharges ${ }^{13}$ and already used for DBD discharges. ${ }^{3}$

\section{ACKNOWLEDGMENTS}

The authors would like to thank Philippe Bérard for useful discussions, Denis Packan (ONERA) for lending one of the power supplies, Eric Moreau (LEA) for help with the design of the glass Pitot tube, and Alain Walton and Erika Jean-Bart for help constructing the setup.
${ }^{1}$ M. Forte, J. Jolibois, J. Pons, E. Moreau, G. Touchard, and M. Cazalens, Exp. Fluids 43, 917 (2007).

${ }^{2}$ T. C. Corke, B. Mertz, and M. P. Patel, Proceedings of the 44th AIAA Aerospace Sciences Meeting and Exhibit, Reno, NV, 9-12 January 2006, AIAA Paper No. 2006-1208.

${ }^{3}$ D. F. Opaits, A. V. Likhanskii, G. Neretti, S. Zaidi, M. N. Schneider, R. B. Miles, and S. O. Macheret, J. Appl. Phys. 104, 043304 (2008).

${ }^{4}$ J. Huang, T. C. Corke, and F. O. Thomas, AIAA J. 44, 1477 (2006).

${ }^{5}$ D. VanNess, T. C. Corke, and S. Morris, Proceedings of the 44th Aerospace Sciences Meeting and Exhibit, Reno, NV, 9-12 January 2006.

${ }^{6}$ S. Lemire, H. D. Vo, and M. W. Benner, Int. J. Rotating Mach. 2009, 247613 (2009).

${ }^{7}$ T. C. Corke, M. L. Post, and D. M. Orlov, Exp. Fluids 46, 1 (2009).

${ }^{8}$ F. O. Thomas, T. C. Corke, M. Iqbal, A. Kozlov, and D. Schatzman, AIAA J. 47, 2169 (2009).

${ }^{9}$ E. Moreau, R. Sosa, and G. Artana, J. Phys. D 41, 115204 (2008).

${ }^{10}$ J. P. Boeuf and L. C. Pitchford, J. Appl. Phys. 97, 103307 (2005).

${ }^{11}$ J.-C. Matéo-Vélez, P. Degond, F. Rogier, A. Seraudie, and F. Thivet, J. Phys. D 41, 035205 (2008).

${ }^{12}$ P. Bérard, D. A. Lacoste, and C. O. Laux, Proceedings of the 38th AIAA Plasmadynamics and Lasers Conference, Miami, FL, 25-28 June 2007, AIAA Paper No. 2006-4611.

${ }^{13}$ D. A. Lacoste, D. Z. Pai, and C. O. Laux, Proceedings of the 42nd Aerospace Sciences Meeting and Exhibit, Reno, NV, 5-8 January 2004, AIAA Paper No. 2004-0354.

${ }^{14}$ COMSOL MULTIPHYSICS Reference Manual Comsol AB, Stockholm, Sweden, 2003.

${ }^{15}$ G. I. Font, C. L. Enloe, and T. E. McLaughlin, Proceedings of the 39th Fluid Dynamics Conference, San Antonio, TX, 22-25 June 2009.

${ }^{16}$ Y. P. Raizer, Gas Discharge Physics (Springer, New York, 1991), Chap. 5, pp. 76-101. 